\title{
The role of hypoxia-inducible factor-2 in digestive system cancers
}

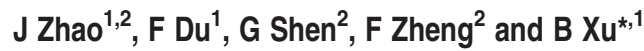

Hypoxia is an all but ubiquitous phenomenon in cancers. Two known hypoxia-inducible factors (HIFs), HIF-1 $\alpha$ and HIF-2 $\alpha$, primarily mediate the transcriptional response to hypoxia. Despite the high homology between HIF-1 $\alpha$ and HIF-2 $\alpha$, emerging evidence suggests differences between both molecules in terms of transcriptional targets as well as impact on multiple physiological pathways and tumorigenesis. To date, much progress has been made toward understanding the roles of HIF-2 $\alpha$ in digestive system cancers. Indeed, HIF- $2 \alpha$ has been shown to regulate multiple aspects of digestive system cancers, including cell proliferation, angiogenesis and apoptosis, metabolism, metastasis and resistance to chemotherapy. These findings make HIF-2 $\alpha$ a critical regulator of this malignant phenotype. Here we summarize the function of HIF-2 during cancer development as well as its contribution to tumorigenesis in digestive system malignancies.

Cell Death and Disease (2015) 6, e1600; doi:10.1038/cddis.2014.565; published online 15 January 2015

\section{Facts}

- Hypoxia is a common phenomenon in digestive system cancers.

- HIF-2a is an essential mediator of the cellular oxygensignaling pathway.

- HIF-2 plays important roles in digestive system cancers and upregulates genes involved in cell proliferation, angiogenesis and apoptosis, metabolism, metastasis and resistance to chemotherapy.

- HIF-2 inhibitors can suppress the expression of HIF-2 target genes to reduce angiogenesis and metastasis.

\section{Open questions}

- Studies assessing the HIF-2a roles in digestive system cancers are scarce, with inconsistent outcomes. Therefore, the actual roles of HIF-2a are still unclear.

- The definite mechanisms of HIF-2 activity during digestive system cancers remain elusive. How does HIF-2 take part in tumorigenesis of digestive system cancers?

- The exploitation of HIF-2a inhibitors faces many challenges.

\section{Introduction to HIF-2a}

HIF-2 is the second member of the hypoxia-inducible factor (HIF) family that includes three proteins: HIF-1, HIF-2 and
HIF-3. Its amino-acid sequence shares $\sim 48 \%$ homology with that of HIF-1. ${ }^{1-3}$ HIF-2 is a heterologous dimeric protein complex that consists of two subunits: HIF-2 $\alpha$ and HIF-1 $\beta$. Both HIF-2 $\alpha$ and HIF-1 $\beta$ belong to the superfamily of transcription factors bHLH-PAS. HIF-2a, also named endothelial PAS domain protein-1 (EPAS1), member of pas superfamily 2 (Mop2), hypoxia-inducible factor $2 a$ subunit or Hif-2- $a$, was identified in 1997. ${ }^{1-4}$ It binds to and activates transcription from the HIF-1a response element derived from the 3-prime flanking region of the EPO gene. Hypoxic conditions stimulate HIF-2 $a$ activation. ${ }^{5}$ Like HIF-1, HIF-2 is primarily regulated by specific prolyl hydroxylase-domain enzymes (PHDs) that initiate its degradation via the von Hippel-Lindau protein (pVHL) tumor suppressor protein. ${ }^{6}$ Under normoxia, PHDs hydroxylate two conserved proline residues (Pro 405 and 531) within HIF-2a, using oxygen, $a$-ketoglutarate and iron as cofactors. HIF-2a hydroxylation facilitates the binding of $\mathrm{pVHL}$ to the HIF-2a $\mathrm{ODD}^{7}$ (Figure 1). The pVHL protein constitutes the substrate recognition module of an E3 ubiquitin ligase complex comprising elongin $\mathrm{C}$, elongin $\mathrm{B}$, cullin-2 and ring-box 1 that directs HIF-2a polyubiquitylation and proteasomal degradation. ${ }^{8}$ With the inhibition of PHD activity and elimination of $\mathrm{pVHL}$ binding under hypoxia, HIF-2 $a$ enters the nucleus and heterodimerizes with HIF- $1 \beta$. Subsequently, HIF-2 $a$ binds to a conserved DNA sequence known as the hypoxiaresponse element (HRE) and transactivates a variety of hypoxia-responsive genes. ${ }^{9}$ As the transcriptional activator

\footnotetext{
${ }^{1}$ Department of Medical Oncology, Cancer Institute and Hospital, Chinese Academy of Medical Science, Peking Union Medical College, Beijing, China and ${ }^{2}$ Affiliated Hospital of Qinghai University, High Altitude Medical Research Center, Xining, China

${ }^{*}$ Corresponding author: B Xu, Department of Medical Oncology, Chinese Academy of Medical Science, Peking Union Medical College, Cancer Institute and Hospital, Beijing 100021, China. Tel: +86 108778 8114; Fax: +86 108771 5711; E-mail: bhxu @ hotmail.com

Abbreviations: CA9, carbonic anhydrase 9; CSC, cancer stem cell; CYP3A4, cytochrome P450 3A4; EPAS1, endothelial PAS domain protein-1; HCC, hepatocellular carcinoma; HIF, hypoxia-inducible factor; HRE, hypoxia-response element; MDR1, multiple drug resistance; PrPc, cellular prion protein; PDA, pancreatic ductal adenocarcinoma; PHD, prolyl hydroxylase-domain enzyme; pVHL, von Hippel-Lindau protein; PXR, pregnane X receptor; RCC, renal cell carcinoma; VEGF, vascular endothelial growth factor

Received 30.10.14; revised 24.11.14; accepted 26.11.14; Edited by E Baehrecke
} 
of erythropoietin, HIF-2 controls intracellular hypoxic responses throughout the body.

HIF-2 $a$ is expressed in endothelial cells, the parenchyma and interstitial cells of multiple organs. ${ }^{1,10,11}$ Although HIF-2a is stabilized at higher $\mathrm{O}_{2}$ pressure compared with HIF-1a in vitro, it was not detected under normoxic conditions in various organs. ${ }^{11-13}$ However, HIF-2a was shown to be markedly induced under hypoxia in all organs investigated, including brain, heart, lung, kidney, liver, pancreas and intestine. $^{11}$

Hypoxia is a common phenomenon in many tumors. The HIF-1 $a$ and HIF-2a proteins are expressed in most types of human tumors, including breast, colon, ovarian, pancreatic, prostate, renal and hepatocellular cancers. ${ }^{14-16}$ Compared with surrounding normal tissues, HIF-1a or HIF-2a (or both) have been detected at higher levels in the majority of primary human cancers and their metastases. ${ }^{14-17}$ HIF-2a mediates the adaptive response to decreased $\mathrm{O}_{2}$ availability at the cellular and organismal level.

\section{HIF-2 Is Different from HIF-1}

The HIF transcription factors mediate the primary transcriptional responses to hypoxic stress in normal and transformed cells. Both HIF-1a and HIF-2a are $\mathrm{O}_{2}$-labile $a$-subunits and heterodimeric complexes composed of bHLH-PAS proteins. In addition, both of them can bind ARNT and mediate transcription. However, increasing evidence has indicated that HIF-2 is distinct or even opposite in many ways from HIF-1. ${ }^{12,18-20}$ To ease understanding, we here delineate the differences between HIF-2 and HIF-1 in three parts. In fact, all the disparities are cause-and-effect relationships and should be conceived as part of a whole in the cellular processes.

First, HIF-2a expression has been shown to differ from that of HIF-1a (Table 1) in various tissues. In contrast to HIF-1a that appears to be expressed in nearly all cell types, HIF-2a expression is restricted to specific types, including endothelial cells, glial cells, type II pneumocytes, cardiomyocytes, kidney fibroblasts, interstitial cells of the pancreas and duodenum and hepatocytes. In the umbilical cord, HIF1a is expressed in smooth muscle cells that surround blood vessels, whereas HIF-2 $a$ was detected in endothelial cells that line blood vessel walls. ${ }^{1-3}$ HIF-1a was observed by cytoplasmic staining in addition to nuclear accumulation; HIF-2a is confined to the cell nucleus and expressed only under hypoxic stimulation. Although HIF-1a is expressed in renal tubules and neuronal cells, HIF-2a was detected in nonparenchymal cells including

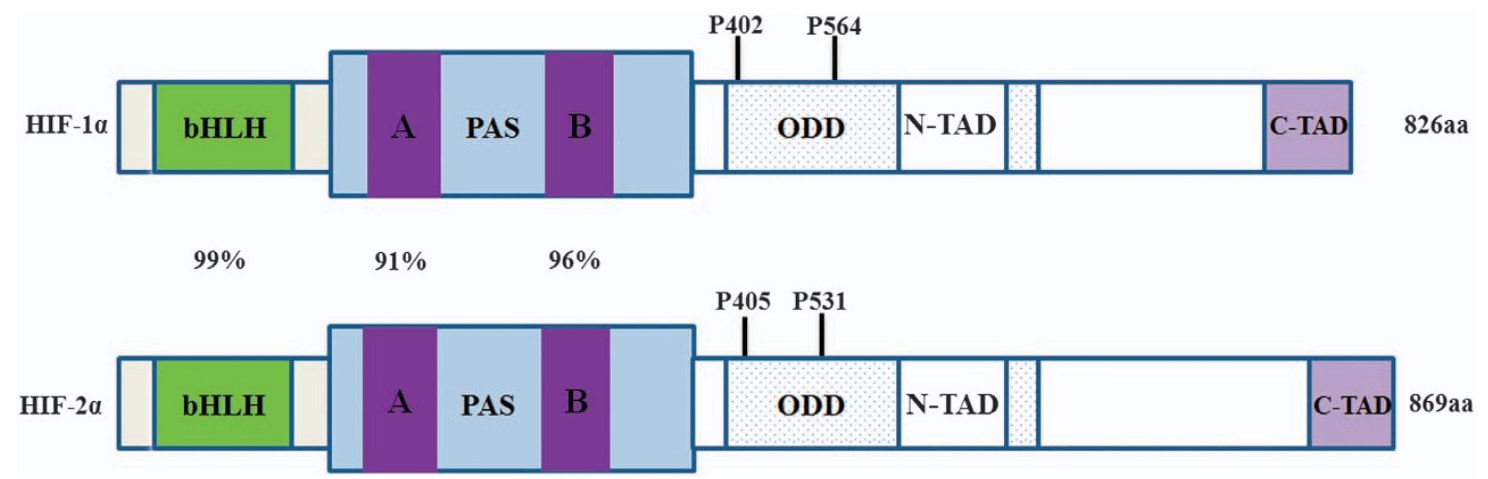

Figure 1 The structural domains of HIF-1 $\alpha$ and HIF-2 $\alpha$. Both of them contain basic helix-loop-helix (bHLH), per-Arnt-SIM (PAS), oxygen-dependent degradation domain (ODD) and C-terminal transactivation domains (CADs). Prolyl hydroxylases (PHDs) hydroxylate proline residues 402 and 564, and 405 and 531, respectively, in ODD of HIF-1 $\alpha$ and HIF-2 $\alpha$, under normoxic conditions, targeting it for degradation by the proteosome, respectively. Numbers refer to amino-acid similarity between human HIF-1 $\alpha$ and HIF-2 $\alpha$ in the defined domains

Table 1 Different expression of HIF-1 $a$ and HIF-2 $a$

\begin{tabular}{|c|c|c|}
\hline HIF-1a & HIF-2a & References \\
\hline \multicolumn{3}{|l|}{ Tissue distribution } \\
\hline Nearly all cell types & $\begin{array}{l}\text { Endothelial cells, glial cells, type II pneumocytes, cardiomyocytes, } \\
\text { fibroblasts of the kidney, interstitial cells of the pancreas and duodenum } \\
\text { and hepatocytes }\end{array}$ & $1-3$ \\
\hline Umbilical cord smooth muscle cells & $\begin{array}{l}\text { and nepatocytes } \\
\text { Endothelial cells }\end{array}$ & $1-3$ \\
\hline Cytoplasm and cell nuclei & Cell nuclei & $1-3$ \\
\hline Renal tubules and neuronal cells & $\begin{array}{l}\text { Kidney glomerular, peritubular endothelial cells and fibroblasts, brain } \\
\text { endothelial cells and glia cells }\end{array}$ & 11 \\
\hline No & Neuroblastoma well-vascularized areas & 12 \\
\hline RCC perinecrotic regions & RCC tumor-associated macrophages & 14 \\
\hline \multicolumn{3}{|l|}{ Oxygen condition } \\
\hline Normoxic baseline conditions & No & 11 \\
\hline More severe hypoxia $\left(6 \% \mathrm{O}_{2}\right)$ in liver and kidney & No & 12 \\
\hline \multicolumn{3}{|l|}{ Time to be activated and duration } \\
\hline Transient in kidney and liver & Sustained in kidney and liver & 11,12 \\
\hline
\end{tabular}


glomerular, kidney peritubular endothelial cells and fibroblasts, and brain endothelial and glial cells. ${ }^{11}$ Furthermore, HIF-2a expression has been shown to differ from that of HIF-1a in many cancers. In addition, HIF-2 is expressed in tumor-associated macrophages, although HIF-1a distribution tends to be more restricted to perinecrotic regions in renal cell carcinoma (RCC). ${ }^{14}$

Another difference concerns the oxygen conditions needed for expression. HIF-1a was shown by immunohistochemistry to be already expressed under normoxic baseline conditions, unlike HIF-2a. ${ }^{11}$ More severe hypoxia $\left(6 \% \mathrm{O}_{2}\right)$ is required to induce HIF-1a compared with HIF-2a in liver and kidney. ${ }^{11}$ HIF-1 $a$ is most active during short periods (2-24 h) of intense hypoxia or anoxia $\left(<0.1 \% \mathrm{O}_{2}\right)$, whereas HIF-2a was shown to be active under mild or physiological hypoxia $\left(<5 \% \mathrm{O}_{2}\right)$ in both SK-N-BE(2)c and KCN-69n neuroblastoma cell lines. ${ }^{12}$ These findings indicate that HIF-2 plays a critical role in driving the hypoxic response, whereas HIF-1 controls the initial response to hypoxia in certain contexts. ${ }^{12,20}$

The two proteins also differ by the time needed for activation and duration of activity. HIF-1a induction in kidney and liver was shown to be transient; however, HIF-2a expression is sustained. ${ }^{11}$ Moreover, HIF-1a was transiently stabilized and primarily mediated acute responses, whereas HIF-2a gradually accumulated and managed prolonged hypoxic gene activation under hypoxia $\left(1 \% \mathrm{O}_{2}\right)$ in neuroblastoma. The activity of HIF-2a persists even after $48-72 \mathrm{~h}$ of hypoxia in neuroblastoma cell lines. ${ }^{12}$

Second, based on their distinct expression patterns, HIF-2a plays different roles in many respects compared with HIF-1a (Table 2). It was found that the majority of hypoxia-induced genes contained HIF-1-binding sites, and gene expression was shown to be dependent on HIF-1a expression. HIF-2a binding was redundant for many genes, but knockdown of HIF-2a levels did not affect gene expression. ${ }^{21}$ In fact, emerging studies have shown that HIF-1 $a$ and HIF-2 $a$ regulate different target genes, with non-redundant and even opposite biological functions. HIF-1a plays more important roles in endothelial cell proliferation, migration and vessel sprouting; HIF-2a plays a more significant role in controlling vascular morphogenesis, integrity and assembly. ${ }^{22}$ Overexpression of
HIF-2 $a$ was shown to enhance the expression of endothelial tyrosine kinase receptor Tie2, in contrast to HIF-1 $a .{ }^{1} \mathrm{HIF}-2 a$ or other hypoxia-induced factors cannot compensate for the loss of HIF-1a, whereas hypoxic induction of HIF-1 $a$ target genes is attenuated in Hif-1a-deficient endothelial cells. ${ }^{23}$ Interestingly, HIF-1a decreased IL-8 expression whereas HIF-2a overexpression increased the mRNA and protein levels of this cytokine in HMEC-1 cells. ${ }^{24}$ HIF-2a also seems to have a stronger transactivation activity than HIF-1a on vascular endothelial growth factor (VEGF) promoter. ${ }^{2,13,25,26}$ Moreover, HIF-2 is the dominant HIF regulating VEGF and other angiogenic factors in mouse liver hemangiomas. ${ }^{27} \mathrm{HIF}-1 a$ facilitates cell growth in vitro and tumorigenesis in vivo, whereas HIF-2 showed opposite effects in colon cancer cells. ${ }^{28}$ Surprisingly, HIF-2a also has distinct or even opposite functions with HIF-1a in some cancers. In RCC, HIF-2a, but not HIF-1a, promotes tumor growth in xenograft models. Overexpression of stable HIF-1a inhibits tumor growth in 786-O RCC cells, ${ }^{29,30}$ whereas overexpression of stable HIF-2aexpressing $\mathrm{pVHL}$ restores xenograft growth to the level of parental VHL-null cells. ${ }^{30-32}$ HIF-2 $a$ expression was shown to increase with the degree of dysplasia in preneoplastic kidney lesions of patients with VHL disease, whereas HIF-1a expression decreased, indicating that HIF-2a plays a role in the transformation of dysplastic cells. ${ }^{30,33} \mathrm{~A}$ similar phenomenon was also observed in hepatocellular carcinoma (HCC) and colorectal cancers as described, though the data did not allow firm conclusion. HIF-1a deficiency inhibited overall tumor growth, whereas deficiency of HIF-2a stimulated tumor growth in colorectal cancers xenograft. ${ }^{28}$ HIF-1a and HIF-2 $a$ are differentially regulated in vivo and reflected distinctive protein expression patterns and stabilization mechanisms in HCC. ${ }^{15,34}$ HIF-2 $a$ also appears to have a more general role in promoting tumorigenesis. Subcutaneous teratomas generated from ES cells with the HIF-2a cDNA 'knocked in' into the Hif-1 $a$ locus exhibited a fourfold mass increase compared with WT RCC 786-O cells controls, mainly because of increased proliferation. $^{35}$ HIF-2a was shown to be stable under prolonged and mild hypoxia conditions in neuroblastoma, and may promote angiogenesis even in tumors experiencing minimal hypoxic stress. ${ }^{12}$ Loss of HIF-1a in endothelial cells

Table 2 Different functions and related target genes between HIF-1 and HIF-2

\begin{tabular}{|c|c|c|c|c|c|}
\hline HIF-1a & HIF-2a & Function & Gene & Cell type & References \\
\hline+ & - & $\begin{array}{l}\text { Endothelial cell proliferation, migration, } \\
\text { and vessel sprouting }\end{array}$ & CXCR4 & Endothelial cell & 22 \\
\hline- & + & $\begin{array}{l}\text { Controlling vascular morphogenesis, } \\
\text { integrity, and assembly }\end{array}$ & CXCR4 & Endothelial cell & 22 \\
\hline - & + & Regulates embryonic vasculature & Tie2 & Embryonic kidney cells & 1 \\
\hline- & + & Increases IL-8 expression & $c-M y c, M x i-1$ & HMEC- 1 cells & 24 \\
\hline- & + & $\begin{array}{l}\text { A stronger transactivation activity on } \\
\text { VEGF promoter }\end{array}$ & $\begin{array}{l}\text { (HIF-2 DNA binding } \\
\text { sequences) }\end{array}$ & $\begin{array}{l}\text { Hepa-1,Hep3, Ka13, fetal kidney cell line mouse, } \\
\text { MG63 Vhlh-deficient mice }\end{array}$ & $2,13,25-27$ \\
\hline+ & - & $\begin{array}{l}\text { Facilitates cell growth and } \\
\text { tumorigenesis }\end{array}$ & CCNG2,ANGPTL4 & SW480, DLD-1 cells & 28 \\
\hline- & + & Promotes tumor growth & $\begin{array}{l}\text { BNip3 transcriptional } \\
\text { regulator }\end{array}$ & $\mathrm{RCC}$ & $29,30-32$ \\
\hline- & + & Transformation of dysplastic cells & Cyclin D1, GLUT-1, & $\mathrm{RCC}$ & 30,33 \\
\hline - & + & Increases proliferation & VEGF, TGF-a & Endothelial cells & 35 \\
\hline - & + & Retards tumor cell migration & iNOS & Endothelial cells & 36 \\
\hline - & + & Angiogenesis & $T G F-\beta 1$ & Prostate tumor & 38 \\
\hline - & + & Regulates stem cell & Oct4, CD133 & Embryos, glioblastoma & 39,40 \\
\hline
\end{tabular}


reduces NO synthesis, retards tumor cell migration through endothelial layers and restricts tumor cell metastasis; however, loss of HIF-2a resulted in opposite effect in each case. ${ }^{36}$ Deficiency of HIF-2a increased tumor growth and progression, whereas HIF-1 $a$ deletion had nearly no effect on tumor burden and progression in a KRAS-driven lung tumor model. ${ }^{37} \mathrm{HIF}-2 a$ signaling, but not HIF-1a, may contribute to tumor angiogenesis via autocrine transforming growth factor- $\beta 1$ (TGF- $\beta 1$ ) production under nonhypoxic conditions in prostate tumor cells. ${ }^{38}$ For cancer stem cells (CSCs), though hypoxia and HIFs may contribute to the maintenance of putative cancer 'stem' cells, HIF-2a seemed also to play a distinct role from $\mathrm{HIF}-1 a$, through unique mechanisms. A recent study revealed that HIF-2a regulates Oct4 directly upstream and binds hypoxic regulatory elements in the promoter of murine Oct4, which is a stem cell regulatory protein; this is not the case for $\mathrm{HIF}-1 a^{39} \mathrm{HIF}-2 a$ may have a specific function in glioblastoma stem cells: it was shown to be selectively expressed in the CD133+ subpopulation of glioblastoma cells, whereas HIF-1a expression is widespread among both tumorigenic and nontumorigenic cells. ${ }^{40}$

Third, HIF-2 $a$ and HIF-1a regulate key downstream genes, including $c-M y c, p 53, m T O R$ and $\beta$-catenin, conversely (Figure 2). For example, HIF-1 $a$ and HIF-2a showed opposite effects on c-Myc interaction with its transcription cofactors. HIF-1 $a$ induction was demonstrated to inhibit c-Myc transcriptional activity and suppress cell proliferation. ${ }^{24,41,42}$ However, HIF-2 $a$ induction promotes cell cycle progression by enhancing c-Myc function. ${ }^{24,43}$ In addition, HIF-2a-mediated suppression of p53 is central to maintenance of the enhanced stemness phenotype in human embryonic stem cells. Unlike HIF-2a, HIF-1a expression declined markedly following reoxygenation in the model ${ }^{44,45}$ (Figure 3 ). HIF-2a may regulate the focal adhesion kinase family interacting protein of $200 \mathrm{kD}$ gene and stimulate mTORC1 to promote cellular proliferation in $\mathrm{O}_{2}$-deprived cells. ${ }^{46}$ On the contrary, HIF-1a induces DDIT4 gene expression and represses mTORC1 by promoting the release of sequestered TSC2 from 14-3-3 proteins. ${ }^{47,48} \mathrm{~A}$ recent study found that HIF-1 negatively regulates $\mathrm{Wnt} / \beta$-catenin signaling by sequestering $\beta$-catenin from $\beta$-catenin/T-cell factor (TCF); instead, HIF-2a interacts with $\beta$-catenin at a different site and assembles with $\beta$-catenin/ TCF to facilitate gene transcription. ${ }^{49}$

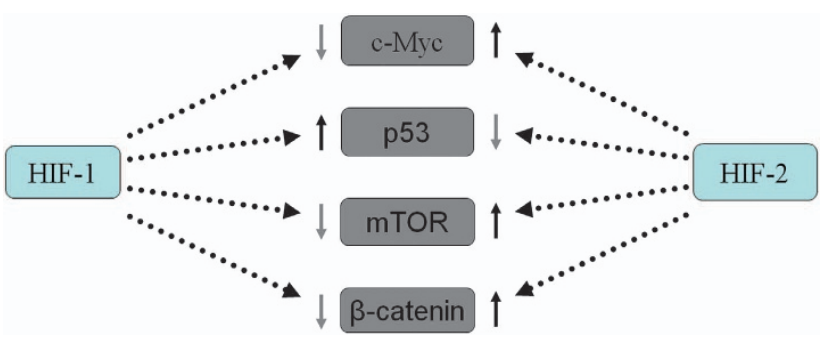

Figure 2 HIF-1 and HIF-2 regulate conversely some key downstream genes. HIF-2 increases $c-M y c$, mTOR and $\beta$-catenin activity and decrease p53 activity, whereas HIF-1 exert opposite effects

\section{HIF-2 $a$ in Digestive System Cancers}

HIF-2 $a$ is frequently detected in most types of solid tumors, including head and neck, renal, bladder, glial, breast, ovarian, prostate and renal cancers. ${ }^{14,15,25,28,50-53}$ An increasing number of studies reporting HIF-2 in the context of digestive system cancer have emerged in recent years and conveyed that this protein plays important roles in digestive system cancers. Interestingly, its prognostic roles are explicit in pancreatic and gastric cancers but confused in colon and hepatocellular cancers (Table 3). HIF-2 upregulates several genes involved in a variety of tumorigenesis events: cell proliferation, angiogenesis, metabolism, metastasis and resistance to chemotherapy (Figure 4).

\section{Proliferation}

Studies have suggested that HIF-2 can regulate cell proliferation through multiple mechanisms, although the outcomes are not identical for all cancers and even controversial in some cases. HIF-2 was shown to be necessary and sufficient to maintain tumor growth in VHL-deficient RCC cells. ${ }^{31,32}$ HIF-2 was shown to control cellular proliferation through modulation of c-Myc activity and cyclin D1 in RCC cells. ${ }^{30,54}$ In addition, new mechanisms for HIF-2 were described in digestive system cancer.

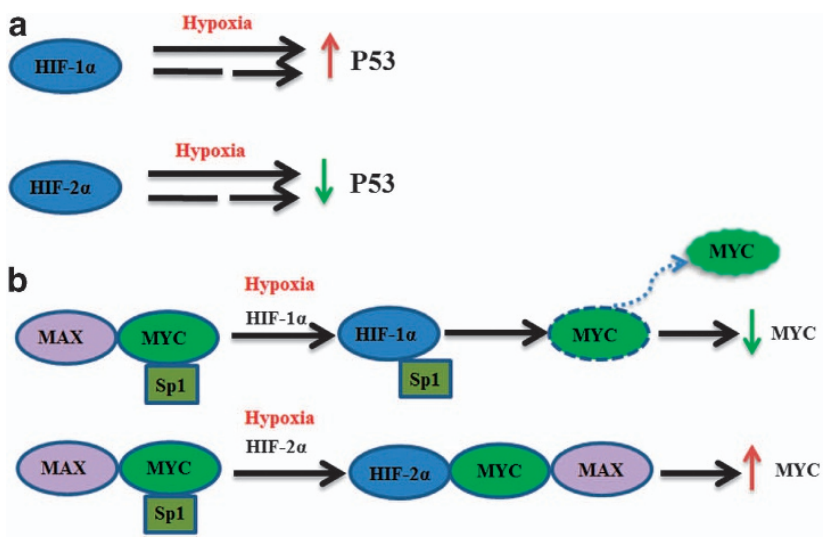

Figure 3 (a) HIF-1 $\alpha$ upregulates P53 activity whereas HIF-2 $\alpha$ downregulates P53 activity under hypoxia directly (full line) or indirectly (dotted line). (b) HIF-1 $\alpha$ and HIF-2 $\alpha$ regulate distinctively c-Myc interacting with its transcription cofactors. HIF-1 $\alpha$ diminishes the association with MAX and SP1, and then decreases MYC activity, whereas HIF-2 $\alpha$ combines with MAX and SP1 complex, thereby increasing MYC activity

Table 3 HIF-2 activation in digestive system cancer

\begin{tabular}{|c|c|c|c|c|}
\hline \multirow[t]{2}{*}{ Cancer } & \multirow[t]{2}{*}{ HIF-2a } & \multicolumn{2}{|c|}{ Prognosis } & \multirow[t]{2}{*}{ References } \\
\hline & & Poor & Good & \\
\hline Gastric & $\uparrow$ & + & - & 18,86 \\
\hline \multirow{3}{*}{ Hepatocellular } & $\uparrow$ & + & - & $14,15,34,78$ \\
\hline & $\uparrow$ & - & + & 60 \\
\hline & $\downarrow$ & + & - & 57 \\
\hline Pancreatic & $\uparrow$ & + & - & 14,56 \\
\hline \multirow{2}{*}{ Colorectal } & $\uparrow$ & + & - & $14,52,64,76,87$ \\
\hline & $\downarrow$ & $\begin{array}{l}T \\
+\end{array}$ & - & 28 \\
\hline
\end{tabular}

The symbol $\uparrow$ indicates upregulation, $\downarrow$ indicates downregulation; + indicates there is correlation and - indicates there is no correlation 


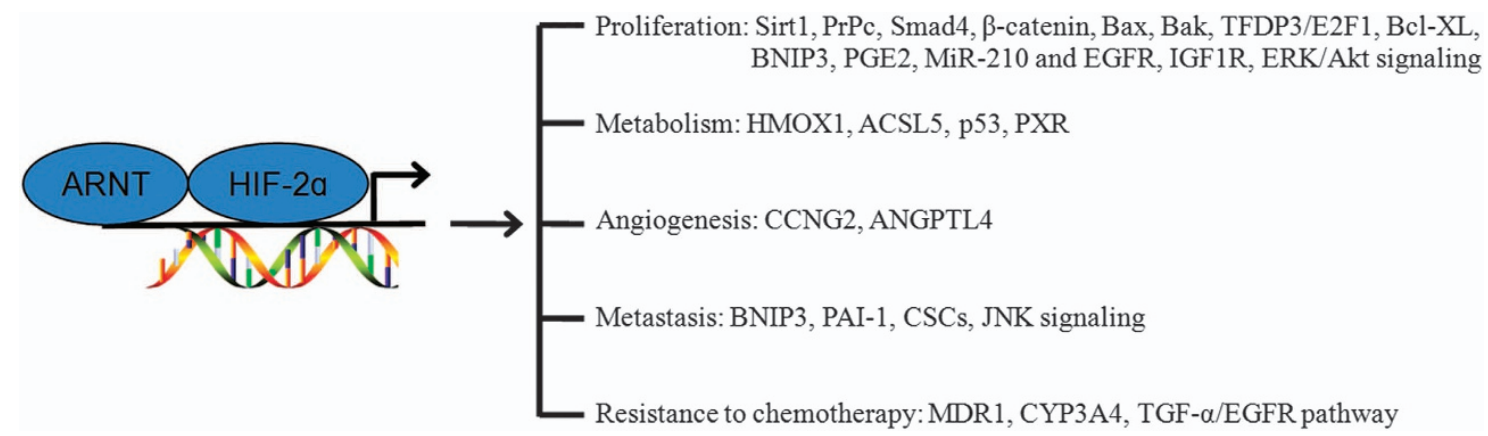

Figure 4 Mechanisms underlying HIF-2 $\alpha$ effect on tumorigenesis in digestive system cancer. HIF-2 $\alpha$ regulates genes that modulate key aspects of tumorigenesis, including proliferation, metabolism, angiogenesis, metastasis and resistance to chemotherapy

A recent study showed that HIF-2 plays opposite roles in different digestive tract cancer cell lines through Sirt1. Sirt1 inhibited HCT116 cell growth but promoted HepG2 cell growth. The cell type-dependent actions of Sirt1 on cell growth may be attributable to its opposite effects on HIF-2a activity in different cell lines. ${ }^{18} \mathrm{PrPc}$ (cellular prion protein) is a glycosylphosphatidylinositol anchored membrane protein with various physical functions. PrPc is highly expressed in colorectal adenocarcinomas. It is involved in regulating Glut1 expression through the Fyn-HIF-2a pathway. ${ }^{55}$

By maintaining appropriate levels of both Smad4 and $\beta$-catenin, HIF-2a modulates the Wnt signaling pathway during $\mathrm{mPanIN}$ progression, with the oncogenic protein Ras expressed in the pancreas. Loss of Hif-2a in mice instead led to markedly higher number of mPanIN lesions. ${ }^{56}$ The average amounts of HIF-2 $a$ at both protein and mRNA levels were significantly lower in tumor than peritumoral tissues in $\mathrm{HCC}$, and the decreased levels were associated with lower overall survival. ${ }^{57}$ Bax and Bak were expressed at higher levels in HCC SMMC-7721 cells with high HIF-2a expression relative to controls. ${ }^{57}$ Both Bax and Bak are pro-apoptotic BCL-2 proteins and would facilitate the release of cytochrome c. The latter triggers cleaved caspase 3 , which is also a key executer of apoptosis detected at higher levels in cells overexpressing HIF-2a. ${ }^{58,59}$ These data confirmed that high levels of HIF-2a in HCC cells cause cell growth arrest through apoptosis. Furthermore, it was suggested that HIF-2a induces apoptosis through a novel TFDP3/E2F1 pathway involving both p53-dependent and -independent modes. Hence, high HIF-2 $a$ expression in HCC was shown to be correlated with a good outcome. ${ }^{57}$. Menrad et al. ${ }^{60}$ found that knockdown of HIF-1 $a$ or HIF-2 $a$ increased cell viability as well as spheroid size and decreased caspase-3 activity. Indeed, HIF-2aknockdown cells upregulated HIF-1 $a$ and enhanced $\mathrm{Bcl}-\mathrm{XL}$ and BNIP3 expression. BNIP3 binds to the Beclin-1/Bcl-XL complex, thereby releasing Beclin-1 that subsequently induces autophagosome formation. ${ }^{61,62}$ However, the role of HIF-2 $a$ in the development of cancer is unclear, and inconsistencies abound in the existing literature. Bangoura et al. ${ }^{15}$ reported that HIF-2 $a$ is overexpressed in pericarcinoma tissues in HCC and significantly correlated with tumor grade and reduced survival in patients with HCC. HIF-2a/EPAS1 itself, to some extent, affects patient survival. ${ }^{15}$

HIF-2 $a$ is overexpressed in colon cancer, ${ }^{14,17}$ and its activation in vivo directly upregulates COX2 expression and facilitates colon tumorigenesis. HIF-2a activates COX2/mPGES-1/PGE2 signaling to facilitate colon tumorigenesis. $^{63}$ In addition, HIF-2 $a$ exerts its proliferative effects through modulating the EGFR, IGF1R and ERK/Akt signaling pathways in colorectal carcinoma, and its inhibition prevents growth and tumorigenesis of colorectal cancer in vivo. ${ }^{64}$ However, an opposite outcome was reported, with HIF-2a-selective knockdown having no effect on cellular proliferation in colorectal cells, although colony formation doubled in soft agar assays. ${ }^{28}$

A research has also investigated the relationship between HIF-2 $a$ and microRNA (miRNA) in digestive system cancers. HIF-2a was shown to mediate miR-210 and $c-M y c$ to participate in neoplasma. MicroRNA-210 is a direct transcriptional target of HIF-2 $a$ and its upregulation led to a switch from Mnt to c-Myc expression during cholestatic cholangiocarcinogenesis in vivo. ${ }^{65}$

At present, inconsistent conclusions have been reached for the role of HIF-2 in digestive system cancers, especially in $\mathrm{HCC}$ and colorectal carcinoma. The function of HIF-2a appears to be cell-type dependent. The different expression patterns and levels of HIF-2 as well as cell-specific cofactors may affect its activity. Indeed, the organism environment is very complex and HIF-2 could be influenced by many other factors. For instance, HCC is often complicated with hepatitis $\mathrm{B}$ or $\mathrm{C}$ and hepatocirrhosis that may also promote a hypoxic response that stabilizes HIFs in oxygen tension. ${ }^{66,67}$ Therefore, HIF-2 may also be involved in these diseases, leading to a complicated network in certain organs.

\section{Metabolism}

HIF-2a plays a critical role in metabolism, modulating the expression of cytochrome $c$ oxidase isoforms so as to maximize the efficiency of the electron transport chain. Defects in this response lead to impaired ATP production and elevated oxidant production in hypoxia. ${ }^{68}$ HIF-2a/ARNT targets (e.g., SOD2) also protect cellular and mitochondrial components during oxidative stress in mice. ${ }^{69}$

Cancer cells shift glucose metabolism from oxidative route to glycolytic pathway, which involves decreased mitochondrial respiration and increased lactate production, even in the presence of oxygen. ${ }^{70,71} \mathrm{HIF}-a$ target genes are involved in the regulation of numerous pathways important for tumor metabolism. ${ }^{72}$ 
HIF-2a depletion downregulated the expression of heme oxygenase (HMOX1) genes that exert antioxidant functions in RCC. $^{73}$ In colon cancer cells, absence of oncogenic KRAS or both HIF-1 $a$ and HIF-2a led to decreased cardiolipin level and inefficient mitochondrial respiration; ACSL5 induction is directly responsible for maintaining cardiolipin level and efficient mitochondrial respiration in cancer. Colon cancer cells with oncogenic KRAS mutation and expressing both HIF-1 $a$ and HIF-2 $a$ were shown to maximize ATP production and minimize ROS generation, probably through the induction of enzymes important for mitochondrial cardiolipin synthesis. $^{74}$

Poorer survival of HIF-2 $a$ and wild-type TP53 was associated with carbonic anhydrase 9 (CA9) stromal-positive colorectal adenocarcinomas. Furthermore, tumors expressing HIF-2a or CA9 in their stroma show poorer prognosis in wildtype TP53 tumors compared with mutant malignancies. It is plausible that p53 is involved in the metabolic switch to glycolysis, when oxidative phosphorylation is impaired during hypoxia $;^{75}$ p53 may simply correlate with defects in another pathway such as the BNIP3 cell death pathway that substitutes for TP53 loss in a similar manner during carcinogenesis. $^{76}$ CYP (cytochrome P450) 3A4 mediates exogenous-drug transportation and oxidative metabolism. We have observed that HIF-2a modulates the recruitment of pregnane $\mathrm{X}$ receptor $(\mathrm{PXR})$ to the $\mathrm{PXR}$ response element in the CYP3A4 (cytochrome P450 3A4) gene promoter region in gastric cancer BGC-823 cells (Jiuda Zhao, unpublished data).

\section{Angiogenesis}

Angiogenesis plays an important role in tumorigenesis and cancer progression. Hypoxia is the prime driving force for tumor angiogenesis, and HIFs play a key role in this process. Growing evidence supports that HIF-2a is involved in angiogenesis. ${ }^{77}$ HIF2 expression was directly correlated with microvessel density and cyclooxygenase 2 expression in colorectal carcinoma, indicating its potential role in angiogenesis of colorectal carcinomas. ${ }^{53}$ Selective knockdown of HIF-2a resulted in more pronounced decrease of VEGF and MVD levels compared with HIF-1 1 repression in colon cancer xenograft studies. HIF-2a exerts these unique effects on colonic tumorigenesis through cyclin G2 (CCNG2) and angiopoietin-like 4 (ANGPTL4), a secreted protein of the angiopoietin-like family induced by hypoxia. ${ }^{28}$ HIF-2 upregulates the expression of VEGF that binds VEGFR and stimulates tumor angiogenesisin in $\mathrm{HCC}^{77}$ Transfection of HIF-2a siRNA into HCC cells was shown to downregulate the expression of VEGF, cyclin D1, HIF-2 $a$ and TGF- $a$, inhibiting the activation of EGFR. ${ }^{78}$ Conditional inactivation of HIF-2a resulted in suppressed development of $\mathrm{VHL}$-associated liver hemangiomas; in addition, angiogenic gene expression in hepatocytes is predominantly regulated by HIF-2 and not HIF-1. It suggests that HIF-2 is the dominant HIF in the pathogenesis of VHL-associated vascular tumors. Hemangioma formation does not require HIF-1a, but is dependent on ARNT, suggesting that HIF-2a may play an essential role in VHL-associated vascular tumorigenesis. ${ }^{79}$ These observations indicate that HIF-2a is an important mediator of angiogenesis in digestive tract cancers.

\section{Metastasis}

Hypoxia is an important microenvironmental factor that induces cancer metastasis. HIF activation correlates with metastasis in multiple tumors and can promote metastasis through the regulation of key factors governing tumor cell metastatic potential, including E-cadherin, LOX, CXCR4, SDF-1 and TWIST in RCC, breast and head/neck cancers. $^{80-85}$

Some studies have indicated that HIF-2 $a$ also participates in digestive tract cancer metastasis by regulating the JNK signaling pathway, BNIP3, PAl-1 and CSCs. In gastric cancer, HIF-1 $a$ and HIF-2a levels are higher in metastasis samples compared with non-metastatic ones. Hypoxia $\left(1 \% \mathrm{O}_{2}, 8 \mathrm{~h}\right)$ was shown to induce HIF-1 $a$ and HIF-2a expression in gastric cancer cell lines. Small interfering RNA (siRNA) against $\mathrm{HIF}-1 a$ and HIF-2 $a$ in gastric cancer cells significantly inhibited hypoxia-induced adhesive and invasive abilities. HIF-2a is therefore involved in metastasis and invasion of gastric cancer cells under hypoxia, in a mechanism involving the JNK signaling pathway. ${ }^{86}$ In primary colorectal cancer, overexpression of HIF-2 $a$ together with BNIP3 was linked to local invasion and lymph node metastasis. ${ }^{87}$

The role of HIF-2 $a$ in HCC is not entirely understood. Some studies have demonstrated that HIF-2a is associated with tumor metastasis, whereas others hold the opposite opinion. A study found that HIF-2 $a$ is overexpressed in HCC compared with noncancerous lesions, and its levels were significantly correlated with tumor grade, venous invasion, intrahepatic metastasis, necrosis and capsule infiltration. ${ }^{15}$ Two HREs at

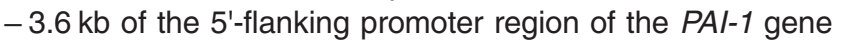
can function as cis-acting elements to regulate $P A /-1$ gene induction by hypoxia in mouse hepatoma cells. The interaction of these HREs with the HIF-1 or HIF-2 protein mediates the transcription of the $P A /-1$ gene that is involved in invasion and metastasis. $^{88}$ However, Yang et al. reported recently that high HIF-2a expression was found in only $13.5 \%(17 / 126)$ of tumors compared with $47.6 \%(60 / 126)$ of peritumoral tissues in HCC samples. There was no relationship between HIF-2a and capsular infiltration or portal vein invasion in $\mathrm{HCC}$ patients. $^{34}$

Another mechanism by which HIF-2 controls metastasis is through modulation of CSCs. It is widely accepted that metastasis originates from CSCs with tumor-initiating capabilities that allow most disseminated tumor cells to reconstitute growing, heterogeneous secondary tumors. ${ }^{89}$ Blocking HIF-1a or HIF-2a activity results in dramatically decreased CSC proliferation and self-renewal in hematological malignancies and glioma stem cells. ${ }^{40,90-92}$ Limited research has indicated that HIF-2 $a$ also plays roles in metastasis of digestive tract cancers by regulating the CSCs. Interestingly, HIF-2a co-stained with CD133 in pancreatic ductal adenocarcinoma (PDA), suggesting that tumor hypoxia is associated with the expression of CSC markers in PDA. Hypoxia-driven EMT occurs in tumor tissues from pancreatic cancer patients, with CSC-positive tumor cells present in hypoxic tumor microenvironments. Only stem-like cells acquire high migratory potential and thus may be responsible for invasion and metastasis. $^{93}$ 


\section{HIF-2 and Resistance to Chemotherapy}

The hypoxic environment plays a critical role in promoting resistance to anticancer drugs. ${ }^{94,95}$ Previous studies have indicated that HIF-2 responds rapidly to decreased oxygen levels to activate the expression of a broad range of genes that promote resistance.

In the case of colon cancer cells, oxaliplatin increased HIF-2 $a$ accumulation and enhanced cell growth; indeed, HIF-2a may mediate, at least partly, oxaliplatin resistance in SW1116 cells. ${ }^{96}$ Disruption of HIF-1 $a$ or HIF-2 $a$ gene, or both, further improved the tumor response to sunitinib therapy in human colon cancer cells. ${ }^{97}$ Upregulation of HIF-2a induced by sorafenib was shown to contribute to resistance of hypoxic HCC cells by activating the TGF-a/EGFR pathway. ${ }^{79}$

To better understand the roles of HIF-2 in chemotherapy resistance, our laboratory studied the relationship between HIF-2 $a$ and multiple drug resistance (MDR1). We found that overexpression of HIF-2 $a$ inhibits the PXR transcriptional activity and reduces the expression of PXR downstream genes, whereas increasing hypoxia elicited MDR1 and CYP3A4 expression. Moreover, overexpression of HIF-2a significantly reduced the pharmacological effects of Paclitaxel, Mitomycin C, Imatinib and Sorafenib on gastric cancer BGC823 cells, and the corresponding $\mathrm{IC}_{50}$ values increased markedly (Jiuda Zhao, unpublished data). Therefore, HIF-2 may serve as a biomarker for a better understanding of chemoresistance in digestive system cancer through MDR1 gene induction.

Taken together, these experimental and clinical data delineate an important role for HIF-2 in chemotherapy resistance through multiple mechanisms and provide a basis for reversing drug resistance with HIF-2 inhibitors.

\section{HIF-2 and Tumor Inhibition}

As HIF complexes are involved in cancer cell adaptation to hypoxic tumor microenvironments, inhibitors of the HIF signaling pathway have been developed and used to inhibit the expression of HIF target genes and reduce angiogenesis and metastasis. ${ }^{98}$ The ability to selectively inhibit HIF activity would be beneficial to clinical treatment. ${ }^{99} \mathrm{~A}$ large collection of compounds have been reported to inhibit HIF transcriptional activity, either directly or indirectly. ${ }^{100-102}$ For example, downregulation of the oncoprotein human double minute 2 reduced the levels of HIF-1 and HIF-2 $a$ in a p53- and VHL-independent manner. ${ }^{103}$ The JNK inhibitor SP 600125 abolished hypoxiainduced HIF-1 $a$ and HIF-2 $a$ expression, and inhibited the adhesive and invasive abilities of gastric cancer cells. ${ }^{86}$ Two new cembrane diterpenes were found to selectively inhibit HIF-2 $a$ and modulate downstream effectors of tumorigenesis. ${ }^{104}$

In addition, agents that inhibit reactive oxygen species generation, such as superoxide dismutase mimetics, have also been shown to decrease HIF levels. ${ }^{105}$ Inducing PHD enzyme activity with derivatives of $a$-ketoglutarate is also a method to target hypoxic areas of tumors, although it reduces signaling through both HIF-1a and $-2 a{ }^{46}$ Overexpression of the tumor suppressor protein pVHL inhibits HCC growth in mice by downregulating HIF-1 $a$ and HIF-2 $a{ }^{106}$

To date, only few inhibitors have been shown to selectively target HIF-2a. Furthermore, although laboratory effects of chemical and biologic inhibitors of HIF-2a on tumor cells are being investigated, clinical grade HIF-2a-specific inhibitors have yet to be developed.

\section{Conclusion and Perspectives}

In conclusion, multitudinous studies have provided persuasive evidence that HIF-2 plays important roles in many critical aspects of digestive system cancers. It is involved in cellular proliferation, metabolism, angiogenesis, metastasis and resistance to drugs. Clinical data also indicated that HIF-2 overexpression is associated with prognosis of digestive system cancers. The HIF-2 pathway may therefore constitute a useful biomarker for assessing disease states as well as developing cancer treatments.

However, multiple questions regarding HIF-2 need to be promptly answered. First, inconsistent associations between HIF-2 and digestive tract cancers have been reported. The study conclusions do not corroborate each other, sometimes for the same organ. This suggests that HIF-2-specific gene activating functions respond differently to various stimuli, with gene- or tissue-specific regulatory mechanisms involving additional transcription factors. Moreover, the limited sample size in different studies and different cell line status in some studies may also affect the results. Second, although data have been amassed delineating the mechanisms and consequences of increased HIF-2 activity during cancer progression, its definite mechanisms remain elusive in digestive system cancers. The role of HIF-2a in the pathogenesis of cancers is extensively studied in RCC, but far too few studies have assessed HIF-2a in digestive system cancers. Third, the exploitation of HIF-2a inhibitors is still challenging. Most inhibitors target nonselectively both HIF-1 $a$ and HIF-2 $a$. HIF targeting involves the overlapping but distinct biological roles of the HIF-a subunits. Compounds that promote the binding of IRP1 to the 5' UTR of HIF-2a mRNA decrease HIF-2 $a$ hypoxic induction, but also repress HIF-1a synthesis via an independent mechanism. ${ }^{107}$ Discriminating between the $a$-subunits and their relative contributions to different digestive system cancers will be important for appropriately testing compounds for use in therapy. The intricate interplay between HIF-1 and HIF-2 should also be studied further. In addition, although another HIF family member, HIF-3, can also dimerize with ARNT and bind to HREs in vitro, ${ }^{108}$ its role in the hypoxic regulation of target gene expression and interaction with HIF-1 and HIF-2 in vivo is not well understood. We believe that further studies are warranted to elucidate the important role of HIF-2 in digestive system cancers. There is still a long way to go before one can confidently promote the clinical application of HIF-2 targeting therapy for digestive system cancers.

\section{Conflict of Interest}

The authors declare no conflict of interest.

Acknowledgements. This work was supported by grants from the National Natural Science Foundation of China (No. 81360318) and Application and Basic Research Program of Qinghai Province in China (No. 2012-Z-739, 2014-Z-745). 
1. Tian H, McKnight SL, Russell DW. Endothelial PAS domain protein 1 (EPAS1), a transcription factor selectively expressed in endothelial cells. Genes Dev 1997; 11: 72-82.

2. Ema M, Taya S, Yokotani N, Sogawa K, Matsuda Y, Fujii-Kuriyama Y. A novel bHLH-PAS factor with close sequence similarity to hypoxia-inducible factor 1alpha regulates the VEGF expression and is potentially involved in lung and vascular development. Proc Natl Acad Sci USA 1997; 94: 4273-4278.

3. Flamme I, Fröhlich T, von Reutern M, Kappel A, Damert A, Risau W. HRF a putative basic helixloop-helix-PAS-domain transcription factor is closely related to hypoxia-inducible factor-1 alpha and developmentally expressed in blood vessels. Mech Dev 1997; 63: $51-60$.

4. Hogenesch JB, Chan WK, Jackiw VH, Brown RC, Gu YZ, Pray-Grant M et al. Characterization of a subset of the basic-helix-loop-helix-PAS superfamily that interacts with components of the dioxin signaling pathway. J Biol Chem 1997; 272: 8581-8593.

5. Gordan JD, Simon MC. Hypoxia-inducible factors: central regulators of the tumor phenotype. Curr Opin Genet Dev 2007; 17: 71-77.

6. Mahon PC, Semenza GL. FIH-1: a novel protein that interacts with HIF-1alpha and VHL to mediaterepression of HIF-1 transcriptional activity. Genes Dev 2001; 15: 2675-2686.

7. Jaakkola P, Mole DR, Tian YM, Wilson MI, Gielbert J, Gaskell SJ et al. Targeting of HIF-alpha to the von Hippel-Lindau ubiquitylation complex by O2-regulated prolyl hydroxylation. Science $2001 ; 292$ : 468-472.

8. Ohh M, Park CW, Ivan M, Hoffman MA, Kim TY, Huang LE et al. Ubiquitination of hypoxiainducible factor requires direct binding to the beta-domain of the von Hippel-Lindau protein. Nat Cell Biol 2000; 2: 423-427.

9. Maxwell PH, Pugh CW, Ratcliffe PJ. Activation of the HIF pathway in cancer. Curr Opin Genet Dev 2001; 11: 293-299.

10. Tian H, Hammer RE, Matsumoto AM, Russell DW, McKnight SL. The hypoxia-responsive transcription factor EPAS1 is essential for catecholamine homeostasis and protection against heart failure during embryonic development. Genes Dev 1998; 12: 3320-3324.

11. Wiesener MS, Jurgensen JS, Rosenberger C, Scholze CK, Horstrup JH, Warnecke C et al. Widespread hypoxia-inducible expression of HIF-2alpha in distinct cell populations of different organs. FASEB J 2003; 17: 271-273.

12. Holmquist-Mengelbier L, Fredlund $E$, Lofstedt $T$, Noguera R, Navarro S, Nilsson $\mathrm{H}$ et al. Recruitment of HIF-1alpha and HIF-2alpha to common target genes is differentially regulated in neuroblastoma: HIF-2alpha promotes an aggressive phenotype. Cancer Cell 2006; 10: 413-423.

13. Wiesener MS, Turley $\mathrm{H}$, Allen WE, Willam C, Eckardt KU, Talks $\mathrm{KL}$ et al. Induction of endothelial PAS domain protein-1 by hypoxia: characterization and comparison with hypoxia-inducible factor-1alpha. Blood 1998; 92: 2260-2268.

14. Talks KL, Turley H, Gatter KC, Maxwell PH, Pugh CW, Ratcliffe PJ. The expression and distribution of the hypoxia-inducible factors HIF-1a and HIF-2a in normal human tissues, cancers, and tumor-associated macrophages. Am J Pathol 2000; 157: 411-421.

15. Bangoura G, Liu ZS, Qian Q, Jiang CQ, Yang GF, Jing S. Prognostic significance of HIF-2alpha/EPAS1 expression in hepatocellular carcinoma. World J Gastroenterol 2007; 13: 3176-3182.

16. Shi CY, Fan Y, Liu B, Lou WH. HIF1 contributes to hypoxia-induced pancreatic cancer cells invasion via promoting QSOX1 expression. Cell Physiol Biochem 2013; 32: 561-568.

17. Zhong H, De Marzo AM, Laughner E, Lim M, Hilton DA, Zagzag D et al. Overexpression of hypoxia-inducible factor 1alpha in common human cancers and their metastases. Cancer Res 1999; 59: 5830-5835.]

18. Yoon H, Shin SH, Shin DH, Chun YS, Park JW. Differential roles of Sirt1 in HIF-1 $\alpha$ and HIF-2 $\alpha$ mediated hypoxic responses. Biochem Biophys Res Commun 2014; 444: 36-43.

19. Eubank TD, Roda JM, Liu H, O'Neil T, Marsh CB. Opposing roles for HIF-1 $\alpha$ and HIF-2 $\alpha$ in the regulation of angiogenesis by mononuclear phagocytes. Blood 2011; 117: 323-332.

20. Koh MY, Lemos R Jr, Liu X, Powis G. The hypoxia-associated factor switches cells from $\mathrm{HIF}-1 \alpha$ - to HIF-2 $\alpha$-dependent signaling promoting stem cell characteristics, aggressive tumor growth and invasion. Cancer Res 2011; 71: 4015-4027.

21. Mole DR, Blancher C, Copley RR, Pollard PJ, Gleadle JM, Ragoussis J et al. Genome-wide association of hypoxia-inducible factor (HIF)-1alpha and HIF-2alpha DNA binding with expression profiling of hypoxia-inducible transcripts. J Biol Chem 2009; 284: 16767-16775.

22. Fraisl $P$, Mazzone M, Schmidt T, Carmeliet $P$. Regulation of angiogenesis by oxygen and metabolism. Dev Cell 2009; 16: 167-179.

23. Tang N, Wang L, Esko J, Giordano FJ, Huang Y, Gerber HP. Loss of HIF-1alpha in endothelial cells disrupts a hypoxia-driven VEGF autocrine loop necessary for tumorigenesis. Cancer Cell 2004; 6: 485-495.

24. Florczyk U, Czauderna S, Stachurska A, Tertil M, Nowak W, Kozakowska M. Opposite effects of HIF-1 $\alpha$ and HIF-2 $\alpha$ on the regulation of IL-8 expression in endothelial cells. Free Radic Biol Med 2011; 51: 1882-1892.

25. Xia G, Kageyama Y, Hayashi T, Kawakami S, Yoshida M, Kihara K. Regulation of vascular endothelial growth factor transcription by endothelial PAS domain protein 1 (EPAS1) and possible involvement of EPAS1 in the angiogenesis of renal cell carcinoma. Cancer 2001; 91: $1429-1436$

26. Akeno N, Czyzyk-Krzeska MF, Gross TS, Clemens TL. Hypoxia induces vascular endothelial growth factor gene transcription in human osteoblast-like cells through the hypoxia-inducible factor 2alpha. Endocrinology 2001; 142: 959-962.

27. Rankin EB, Rha J, Unger TL, Wu CH, Shutt HP, Johnson RS et al. Hypoxia- inducible factor-2 regulates vascular tumorigenesis in mice. Oncogene 2008; 27: 5354-5358.
28. Imamura T, Kikuchi H, Herraiz MT, Park DY, Mizukami Y, Mino-Kenduson M et al. HIF-1 $\alpha$ and HIF-2 $\alpha$ have divergent roles in colon cancer. Int J Cancer 2009; 124: 763-771.

29. Maranchie JK, Vasselli JR, Riss J, Bonifacino JS, Linehan WM, Klausner RD. The contribution of VHL substrate binding and HIF1-alpha to the phenotype of VHL loss in renal cell carcinoma. Cancer Cell 2002; 1: 247-255.

30. Raval RR, Lau KW, Tran MG, Sowter HM, Mandriota SJ, Li JL et al. Contrasting properties of hypoxia-inducible factor 1 (HIF-1) and HIF-2 in von Hippel-Lindau-associated renal cell carcinoma. Mol Cell Biol 2005; 25: 5675-5686.

31. Kondo K, Klco J, Nakamura E, Lechpammer M, Kaelin WG Jr. Inhibition of HIF is necessary for tumor suppression by the von Hippel-Lindau protein. Cancer Cell 2002; 1: 237-246.

32. Kondo K, Kim WY, Lechpammer M, Kaelin WG Jr. Inhibition of HIF2alpha is sufficient to suppress pVHL-defective tumor growth. PLOS Biol 2003; 1: E83.

33. Mandriota SJ, Turner KJ, Davies DR, Murray PG, Morgan NV, Sowter HM et al. HIF activation identifies early lesions in VHL kidneys: evidence for site-specific tumor suppressor function in the nephron. Cancer Cell 2002; 1: 459-468.

34. Yang SL, Liu LP, Jiang JX, Xiong ZF, He QJ, Wu C. The correlation of expression levels of HIF-1 $\alpha$ and HIF-2 $\alpha$ in hepatocellular carcinoma with capsular invasion, portal vein tumor thrombi and patients' clinical outcome. Jpn J Clin Oncol 2014; 44: 159-167.

35. Covello KL, Simon MC, Keith B. Targeted replacement of hypoxia-inducible factor-1alpha by a hypoxia-inducible factor-2alpha knock-in allele promotes tumor growth. Cancer Res 2005; 65: 2277-2286.

36. Branco-Price C, Zhang N, Schnelle M, Evans C, Katschinski DM, Liao D et al. Endothelial cell HIF-1 $\alpha$ and HIF-2 $\alpha$ differentially regulate metastatic success. Cancer Cell 2012; 21: $52-65$.

37. Mazumdar J, Hickey MM, Pant DK, Durham AC, Sweet-Cordero A, Vachani A et al. HIF-2alpha deletion promotes Kras-driven lung tumor development. Proc Natl Acad Sci USA 2010; 107: 14182-14187.

38. Chae KS, Kang MJ, Lee JH, Ryu BK, Lee MG, Her NG et al. Opposite functions of HIF- $\alpha$ isoforms in VEGF induction by TGF- $\beta 1$ under non-hypoxic conditions. Oncogene 2011; 30 1213-1328.

39. Mazumdar J, Dondeti V, Simon MC. Hypoxia-inducible factors in stem cells and cancer. J Cell Mol Med 2009; 13: 4319-4328.

40. Li Z, Bao S, Wu Q, Wang H, Eyler C, Sathornsumetee S et al. Hypoxia-inducible factors regulate tumorigenic capacity of glioma stem cells. Cancer Cell 2009; 15: 501-513.

41. Koshiji M, Kageyama Y, Pete EA, Horikawa I, Barrett JC, Huang LE. HIF-1alpha induces cell cycle arrest by functionally counteracting Myc. EMBO J 2004; 23: 1949-1956.

42. Koshiji M, To KK, Hammer S, Kumamoto K, Harris AL, Modrich P et al. HIF-1alpha induces genetic instability by transcriptionally downregulating MutSalpha expression. Mol Cell 2005; 77: 793-803.

43. Gordan JD, Bertout JA, Hu CJ, Diehl JA, Simon MC. HIF-2alpha promotes hypoxic cell proliferation by enhancing C-Myc transcriptional activity. Cancer Cell 2007; 11: 335-347.

44. Cummins EP. HIF-2 $\alpha$-a mediator of stem cell altruism? Stem Cell Res Ther 2012; 3: 52.

45. Das B, Bayat-Mokhtari R, Tsui M, Lotfi S, Tsuchida R, Felsher DW. HIF-2 $\alpha$ suppresses $p 53$ to enhance the stemness and regenerative potential of human embryonic stem cells. Stem Cells 2012; 30: 1685-1695.

46. Gan B, Melkoumian ZK, Wu X, Guan KL, Guan JL. Identification of FIP200 interaction with the SC1-TSC2 complex and its role in regulation of cell size control. J Cell Biol 2005; 170: 379-389.

47. Brugarolas J, Lei K, Hurley RL, Manning BD, Reiling JH, Hafen E et al. Regulation of mTOR function in response to hypoxia by REDD1 and the TSC1rrSC2 tumor suppressor complex Genes Dev 2004; 18: 2893-2904.

48. De Young MP, Horak P, Sofer A, Sgroi D, Ellisen LW. Hypoxia regulates TSC1/2-mTOR signaling and tumor suppression through REDD1-mediated 14-3-3 shuttling. Genes Dev 2008; 22: 239-251.

49. Choi H, Chun YS, Kim TY, Park JW. HIF-2alpha enhances beta-catenin/TCF- driven transcription by interacting with beta-catenin. Cancer Res 2010; 70: 10101-10111.

50. Liu YL, Yu JM, Song XR, Wang XW, Xing LG, Gao BB. Regulation of the chemokine receptor CXCR4 and metastasis by hypoxia-inducible factor in non small cell lung cancer cell lines. Cancer Biol Ther 2006; 5: 1320-1326.

51. Winter SC, Shah KA, Han C, Campo L, Turley H, Leek R et al. The relation between hypoxia inducible factor (HIF)-1alpha and HIF-2alpha expression with anemia and outcome in surgically treated head and neck cancer. Cancer 2006; 107: 757-766.

52. Hui EP, Chan AT, Pezzella F, Turley H, To KF, Poon TC et al. Coexpression of hypoxiainducible factors 1alpha and 2alpha, carbonic anhydrase IX, and vascular endothelial growth factor in nasopharyngeal carcinoma and relationship to survival. Clin Cancer Res 2002; 8: 2595-2604.

53. Yoshimura $\mathrm{H}$, Dhar DK, Kohno H, Kubota H, Fujii T, Ueda $\mathrm{S}$ et al. Prognostic impact of hypoxiainducible factors 1alpha and 2alpha in colorectal cancer patients: correlation with tumor angiogenesis and cyclooxygenase-2 expression. Clin Cancer Res 2004; 10: 8554-8560.

54. Arabi A, Wu S, Ridderstråle K, Bierhoff $\mathrm{H}$, Shiue $\mathrm{C}$, Fatyol $\mathrm{K}$ et al. c-Myc associates with ribosomal DNA and activates RNA polymerase I transcription. Nat Cell Biol 2005; 7 303-310.

55. Li QQ, Sun YP, Ruan CP, Xu XY, Ge JH, He J et al. Cellular prion protein promotes glucose uptake through the Fyn-HIF-2 $\alpha$-Glut1 pathway to support colorectal cancer cell survival. Cancer Sci 2011; 102: 400-406. 
56. Criscimanna A, Duan LJ, Rhodes JA, Fendrich V, Wickline E, Hartman DJ. PanIN-specific regulation of Wnt signaling by HIF2 $\alpha$ during early pancreatic tumorigenesis. Cancer Res 2013; 73: 4781-4790

57. Sun HX, Xu Y, Yang XR, Wang WM, Bai H, Shi RY et al. Hypoxia inducible factor 2 alpha inhibits hepatocellular carcinoma growth through the transcription factor dimerization partner 3/ E2F transcription factor 1-dependent apoptotic pathway. Hepatology 2013; 57 1088-1097.

58. Mignotte B, Vayssiere JL. Mitochondria and apoptosis. Eur J Biochem 1998; 252: 1-15.

59. Jurgensmeier JM, Xie Z, Deveraux Q, Ellerby L, Bredesen D, Reed JC. Bax directly induces release of cytochrome c from isolated mitochondria. Proc Natl Acad Sci USA 1998; 95 4997-5002.

60. Menrad H, Werno C, Schmid T, Copanaki E, Deller T, Dehne $\mathrm{N}$ et al. Roles of hypoxiainducible factor-1alpha (HIF-1alpha) versus HIF-2alpha in the survival of hepatocellular tumor spheroids. Hepatology 2010; 51: 2183-2192.

61. Zhang H, Bosch-Marce M, Shimoda LA, Tan YS, Baek JH, Wesley JB et al. Mitochondrial autophagy is an HIF-1-dependent adaptive metabolic response to hypoxia. J Biol Chem 2008; 283: 10892-108903.

62. Mazure NM, Pouysségur J. Atypical BH3-domains of BNIP3 and BNIP3L lead to autophagy in hypoxia. Autophagy 2009; 5: 868-869.

63. Xue X, Shah YM. Hypoxia-inducible factor-2 $\alpha$ is essential in activating the COX2/ mPGES-1/PGE2 signaling axis in colon cancer. Carcinogenesis 2013; 34: 163-169.

64. Franovic A, Holterman CE, Payette J, Lee S. Human cancers converge at the HIF-2alpha oncogenic axis. Proc Natl Acad Sci USA 2009; 106: 21306-21311.

65. Yang H, Li TW, Peng J, Tang X, Ko KS, Xia M et al. A mouse model of cholestasisassociated cholangiocarcinoma and transcription factors involved in progression. Gastroenterology 2011; 141: 378-388.

66. Jungermann K, Kietzmann T. Oxygen: modulator of metabolic zonation and disease of the liver. Hepatology 2000; 31: 255-260.

67. Qu A, Taylor M, Xue X, Matsubara T, Metzger D, Chambon P et al. Hypoxiainducible transcription factor 2alpha promotes steatohepatitis through augmenting lipid accumulation, inflammation, and fibrosis. Hepatology 2011; 54: 472-483.

68. Gordan JD, Thompson CB, Simon MC. HIF and c-Myc: sibling rivals for control of cance cell metabolism and proliferation. Cancer Cell 2007; 12: 108-113.

69. Scortegagna M, Ding K, Oktay Y, Gaur A, Thurmond F, Yan LJ et al. Multiple organ pathology, metabolic abnormalities and impaired homeostasis of reactive oxygen species in Epas1 - / - mice. Nat Genet 2003; 35: 331-340.

70. Warburg O. On the origin of cancer cells. Science 1956; 123: 309-314

71. Shaw RJ. Glucose metabolism and cancer. Curr Opin Cell Biol 2006; 18: 598-608.

72. Weidemann A, Johnson RS. Biology of HIF-1alpha. Cell Death Differ 2008; 15: 621-627.

73. Bertout JA, Majmundar AJ, Gordan JD, Lam JC, Ditsworth D, Keith B et al. HIF2 alpha inhibition promotes p53 pathway activity, tumor cell death, and radiation responses. Proc Natl Acad Sci USA 2009; 106: 14391-14396.

74. Chun SY, Johnson C, Washburn JG, Cruz-Correa MR, Dang DT, Dang LH. Oncogenic KRAS modulates mitochondrial metabolism in human colon cancer cells by inducing HIF-1 $\alpha$ and HIF-2 $\alpha$ target genes. Mol Cancer 2010; 9: 293.

75. Lum JJ, Bui T, Gruber M, Gordan JD, DeBerardinis RJ, Covello KL et al. The transcription factor HIF-1a plays a critical role in the growth factor-dependent regulation of both aerobic and anaerobic glycolysis. Genes Dev 2007; 21: 1037-1049.

76. Cleven AH, Wouters BG, Schutte B, Spiertz AJ, van Engeland M, de Bruïne AP. Poorer outcome in stromal HIF-2 alpha- and CA9-positive colorectal adenocarcinomas is associated with wild-type TP53 but not with BNIP3 promoter hypermethylation or apoptosis Br J Cancer 2008; 99: 727-733.

77. Keith B, Johnson RS, Simon MC. HIFl $\alpha$ and HIF2 $\alpha$ : sibling rivalry in hypoxic tumour growth and progression. Nat Rev 2012; 12: 9-22.

78. Zhao D, Zhai B, He C, Tan G, Jiang X, Pan S et al. Upregulation of HIF-2 $\alpha$ induced by sorafenib contributes to the resistance by activating the TGF- $\alpha / E G F R$ pathway in hepatocellular carcinoma cells. Cell Signal 2014; 26: 1030-1039.

79. Rankin EB, Biju MP, Liu Q, Unger TL, Rha J, Johnson RS et al. Hypoxia-inducible factor-2 (HIF-2) regulates hepatic erythropoietin in vivo. J Clin Invest 2007; 117: 1068-1077.

80. Imai T, Horiuchi A, Wang C, Oka K, Ohira S, Nikaido T et al. Hypoxia attenuates the expression of E-cadherin via up-regulation of SNAIL in ovarian carcinoma cells. Am J Pathol 2003; 163: 1437-1447.

81. Esteban MA, Tran MG, Harten SK, Hill P, Castellanos MC, Chandra A et al. Regulation of Ecadherin expression by VHL and hypoxia-inducible factor. Cancer Res 2006; 66 : 3567-3575.

82. Arya $\mathrm{M}$, Ahmed $\mathrm{H}$, Silhi N, Williamson M, Patel HR. Clinical importance and therapeutic implications of the pivotal CXCL12-CXCR4 (chemokine ligand-receptor) interaction in cancer cell migration. Tumour Biol 2007; 28: 123-131.

83. Ceradini DJ, Kulkarni AR, Callaghan MJ, Tepper OM, Bastidas N, Kleinman ME et al. Progenitor cell trafficking is regulated by hypoxic gradients through HIF-1 induction of SDF-1. Nat Med 2004; 10: 858-864.

84. Staller P, Sulitkova J, Lisztwan J, Moch H, Oakeley EJ, Krek W. Chemokine receptor CXCR4 downregulated by von Hippel-Lindau tumour suppressor pVHL. Nature 2003; 425: 307-311.

85. Erler JT, Bennewith KL, Nicolau M, Dornhofer N, Kong C, Le QT et al. Lysyl oxidase is essential for hypoxia-induced metastasis. Nature 2006; 440: 1222-1226.
86. Wang $\mathrm{Y}$, Li Z, Zhang $\mathrm{H}$, Jin $\mathrm{H}$, Sun L, Dong $\mathrm{H}$ et al. HIF-1 $\alpha$ and HIF-2 $\alpha$ correlate with migration and invasion in gastric cancer. Cancer Biol Ther 2010; 15: 376-382.

87. Kourakis MI, Giatromanolaki A, Polychronidis A, Simopoulos C, Gatter KC, Harris AL et al. Endogenous markers of hypoxia/anaerobic metabolism and anemia in primary colorectal cancer. Cancer Sci 2006; 97: 582-588.

88. Ahn YT, Chua MS, Whitlock JP Jr, Shin YC, Song WH, Kim Y, Eom CY et al. Rodentspecific hypoxia response elements enhance PAl-1 expression through HIF-1 or HIF-2 in mouse hepatoma cells. Int J Oncol 2010; 37: 1627-1638.

89. Li F, Tiede B, Massague J, Kang Y. Beyond tumorigenesis: cancer stem cells in metastasis. Cell Res 2007; 17: 3-14.

90. Heddleston JM, Li Z, Lathia JD, Bao S, Hjelmeland AB, Rich JN. Hypoxia inducible factors in cancer stem cells. Br J Cancer 2010; 102: 789-795.

91. Keith B, Simon MC. Hypoxia-inducible factors, stem cells, and cancer. Cell 2007; 129: 465-472.

92. Koh MY, Powis G. Passing the baton: the HIF switch. Trends Biochem Sci 2012; 37: 364-472

93. Salnikov AV, Liu L, Platen M, Gladkich J, Salnikova O, Ryschich E et al. Hypoxia induces EMT in low and highly aggressive pancreatic tumor cells but only cells with cancer stem cell characteristics acquire pronounced migratory potential. PLoS One 2012; 7: e46391.

94. Wilson WR, Hay MP. Targeting hypoxia in cancer therapy. Nat Rev Cancer 2011; 11: $393-410$

95. Rankin EB, Giaccia AJ. The role of hypoxia-inducible factors in tumorigenesis. Cell Death Differ 2008; 15: 678-685.

96. Wen YA, Stevens PD, Gasser ML, Andrei R, Gao T. Downregulation of PHLPP expression contributes to hypoxia-induced resistance to chemotherapy in colon cancer cells. Mol Cell Biol 2013; 33: 4594-4605.

97. Burkitt K, Chun SY, Dang DT, Dang LH. Targeting both HIF-1 and HIF-2 in human colon cancer cells improves tumor response to sunitinib treatment. Mol Cancer Ther 2009; 8: $1148-1156$

98. Rapisarda A, Uranchimeg B, Scudiero DA, Selby M, Sausville EA, Shoemaker RH et al. Identification of small molecule inhibitors of hypoxia-inducible factor 1 transcriptional activation pathway. Cancer Res 2002; 62: 4316-4324.

99. Semenza GL. Defining the role of hypoxia-inducible factor 1 in cancer biology and therapeutics. Oncogene 2010; 29: 625-634.

100. Kong X, Lin Z, Liang D, Fath D, Sang N, Caro J. Histone deacetylase inhibitors induce VHL and ubiquitin-independent proteasomal degradation of hypoxia-inducible factor 1 alpha. $\mathrm{Mol}$ Cell Biol 2006; 26: 2019-2028.

101. Qian DZ, Kachhap SK, Collis SJ, Verheul HM, Carducci MA, Atadja P et al. Class II histone deacetylases are associated with $\mathrm{VHL}$-independent regulation of hypoxia-inducible factor 1 alpha. Cancer Res 2006; 66: 8814-8821.

102. Härter $M$, Thierauch $\mathrm{KH}$, Boyer $\mathrm{S}$, Bhargava $\mathrm{A}$, Ellinghaus $\mathrm{P}$, Beck $\mathrm{H}$ et al. Inhibition of hypoxia-induced gene transcription by substituted pyrazolyl oxadiazoles: initial lead generation and structure-activity relationships. ChemMedChem 2014; 9: 61-66.

103. Philips GK, Atkins MB. New agents and new targets for renal cell carcinoma. Am Soc Clin Oncol Educ Book 2014: e222-e227.

104. Grkovic T, Whitson EL, Rabe DC, Gardella RS, Bottaro DP, Linehan WM et al. Identification and evaluation of soft coral diterpenes as inhibitors of HIF-2 $\alpha$ induced gene expression. Bioorg Med Chem Lett 2011; 21: 2113-2115.

105. Rabbani ZN, Spasojevic I, Zhang X, Moeller BJ, Haberle S, Vasquez-Vivar J et al. Antiangiogenic action of redox-modulating $\mathrm{Mn}$ (III) meso-tetrakis (Nethylpyridinium-2-yl) porphyrin, MnTE-2-PyP(5+), via suppression of oxidativestress in a mouse model of breast tumor. Free Radic Biol Med 2009; 47: 992-1004.

106. Wang J, Ma Y, Jiang H, Zhu H, Liu L, Sun B et al. Overexpression of von Hippel-Lindau protein synergizes with doxorubicin to suppress hepatocellular carcinoma in mice. $J$ Hepatol 2011; 55: 359-368.

107. Bhatt RS, Landis DM, Zimmer M, Torregrossa J, Chen S, Sukhatme VP et al. Hypoxiainducible factor-2alpha: effect on radiation sensitivity and differential regulation by an $\mathrm{mTOR}$ inhibitor. BJU Int 2008; 102: 358-363.

108. Gu YZ, Moran SM, Hogenesch JB, Wartman L, Bradfield CA. Molecular characterization and chromosomal localization of a third alpha-class hypoxia inducible factor subunit HIF3alpha. Gene Expr 1998; 7: 205-213.

Cell Death and Disease is an open-access journal published by Nature Publishing Group. This work is licensed under a Creative Commons Attribution 4.0 International Licence. The images or other third party material in this article are included in the article's Creative Commons licence, unless indicated otherwise in the credit line; if the material is not included under the Creative Commons licence, users will need to obtain permission from the licence holder to reproduce the material. To view a copy of this licence, visit http://creativecommons.org/licenses/by/4.0 